\title{
Wel of geen achteropplaatsing? Kanttekeningen bij: Evie Coussé 'De extrapositie van het subject in passieve zinnen'
}

WALTER HAESERYN*

Bij de beschrijving van de woordvolgorde (eigenlijk: de constituentenvolgorde) in de zin wordt in de Nederlandse (en Duitse) taalkunde gewoonlijk gebruikgemaakt van een zinsschema met verschillende abstracte plaatscategorieën. Cruciaal voor dat schema zijn de typische plaatsingskenmerken van de werkwoordelijke elementen enerzijds (voor-pv, achter-pv, werkwoordclusters) en de elementen die een bijzin met een hoofdzin verbinden (de 'bindtermen') anderzijds. Die elementen staan ofwel op een vaste plaats vooraan in de zin (de eerste pool(plaats) genoemd) ofwel op een vaste plaats achteraan (de tweede pool(plaats)). Uitgaand van die twee vaste ankerpunten kan de zin verder in drie stukken opgedeeld worden - voor de eerste pool, tussen beide polen in en na de tweede pool -, die respectievelijk eerste zinsplaats, middenstuk en laatste zinsplaats (bijv. in de ANS 1997: 1228) of voorveld, middenveld en achterveld (bijv. in Vandeweghe 2004: 241 e.v.) genoemd worden. ${ }^{1}$

Het zinsschema mag dan een adequaat instrument bieden voor de beschrijving van de plaatsing van elementen in het hedendaagse Nederlands (en Duits) - ook al doen zich soms wel problemen voor -, maar als we het willen toepassen op oudere taalstadia, is voorzichtigheid geboden. De vaste plaats van de persoonsvorm achteraan in bijzinnen (achter-pv) is immers iets wat zich in de loop van de tijd ontwikkeld heeft. Van der Horst (2008: 339; 546) wijst erop dat de persoonsvorm steeds verder naar achteren opgeschoven is en dat er aanvankelijk veeleer sprake is van een positie 'niet op de tweede plaats' dan van een duidelijke eindpositie. Dat houdt mijns inziens in dat er wat de plaatsing van niet-werkwoordelijke elementen betreft dan ook niet echt van een laatste zinsplaats of achterveld, laat staan van achteropplaatsing of extrapositie gesproken kan worden, maar dat het wellicht beter is om te kijken hoeveel en welke elementen er achter de werkwoorden (kunnen) staan en wat hun onderlinge positie is. In ouder Nederlands kon namelijk afgezien van pronomina heel veel achter de werkwoorden staan. Ter illustratie geef ik twee voorbeelden uit Coussé (2009):2

(1) | dat | ic |hebbe ontfanghen|van der steide van ypre in de name ende ouer suster kateline de ruusse nonne in onsen cloester xxiiij lb par als van den paiemente dat

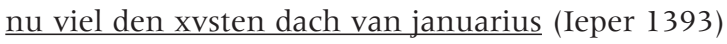

* Radbout Universiteit Nijmegen, Uinversitair docent bij de afdeling Nedrlandse taal en cultuur, redacteur van de ANS.

1 De twee perifere plaatcategorieën, aanloop en uitloop, laat ik hier buiten beschouwing.

2 In deze en in alle volgende voorbeelden heb ik verticale streepjes toegevoegd om de plaats van bindterm en werkwoorden te markeren. 
(2) $\quad \mid$ Dat $\mid$ wi $\mid$ ghesien ende ghehoert hebben|jnt iaer ons heren M ccc ende zouen endetwintich des saterdaghes vor sente laurens dach eenen brief beseghelt met vroeder lude seghel ende reckeliker Goet (...) (Gouda 1327)

In hedendaags Nederlands is de positie achter de tweede pool zoals bekend nagenoeg gereserveerd voor voorzetselconstituenten en bijzinnen als zinsdeel of zinsdeelstuk. Dat neemt niet weg dat (nog steeds) ook naamwoordelijke constituenten op die plaats kunnen voorkomen, zowel indefiniete als definiete en zowel objecten als subjecten, bijvoorbeeld:

(3) Voor de zoektocht $\mid$ moet $\mid$ je in ieder geval |meenemen| een kompas, een zaklamp en voldoende water.

(4) In de tekst $\mid$ zijn $\mid$ - |opgenomen| de inheemse bloemplanten van de Alpen en de Karpaten, het Tatra-gebergte, de Jura, de Cevennen, de Pyreneeën, het Cantabrisch gebergte, de Vogezen en de hogere gebergten van Groot-Brittannië en Noord-Europa. [uit: Bergflora van Europa, 2010]

(5a) De volgende kandidaten |zijn| voor het examen |geslaagd:| Pim Aarns, Carolien Jansen, (...) en Wim van Ooijen.

(5b) De volgende kandidaten |zijn| - |geslaagd| voor het examen: Pim Aarns, Carolien Jansen, (...) en Wim van Ooijen.

(6) |Hebben| het examen |gehaald:| Pim Aarns, Carolien Jansen, (...) en Wim van Ooijen.

In zulke gevallen gaat het steeds om een opsomming, dus om per definitie uitgebreide elementen die bovendien informatief prominent zijn, anders gezegd in focus staan. Hier werken dus twee woordvolgordeprincipes samen die allebei bevorderen dat een element verder naar achteren in de zin komt te staan: het complexiteitsprincipe en het links-rechtsprincipe of informatiegeledingsprincipe (zie de ANS: 1235 e.v.; 1245-1246). In (5b) staat de nominale opsomming tegelijk met een voorzetselconstituent achter de tweede pool en is het middenstuk van de zin leeg, waardoor het informatief belangrijkste zinsdeel als het ware nog verder naar rechts opschuift.

Er is overigens nog een andere strategie mogelijk om de informatieve kern zo ver mogelijk achteraan in de zin te krijgen. Die bestaat erin dat een deelwoord vooraan vóór de eerste pool van de zin geplaatst wordt (bijvoorbeeld $(5 c)$ ), eventueel samen met andere elementen (bijvoorbeeld (7)). Dan is er een lege tweede pool, waardoor niet meer duidelijk uit te maken is of het element achteraan in de zin nu aan het eind van het middenstuk, dan wel in extrapositie staat (vergelijk ANS 1997: 1282-1283).

(5c) Geslaagd |zijn:| Pim Aarns, Carolien Jansen, (...) en Wim van Ooijen.

(7) Niet aan het examen deelgenomen |hebben|Jelko Arts, Sabine De Cock, (...) en Jaap Zeldenrust. 
Vergelijkbare gevallen, die veelvuldig voorkomen in journalistiek en ambtelijk taalgebruik, zijn zinnen als de volgende (voorbeelden uit de ANS 1997: 1284):

(8) Gedacht $\mid$ wordt $\mid$ aan een verhoging van de olieprijs met tien dollar per barrel.

(9) Aangenomen $\mid$ wordt $\mid$ dat de voorzitter ontvoerd is.

(10) Verwacht $\mid$ wordt $\mid$ dat de prijzen voor koffie en thee eind deze maand verder de hoogte in zullen gaan.

Het betreft passieve constructies zonder uitgedrukt onderwerp of (meestal?) met een bijzin als onderwerp. ${ }^{3}$ Die bijzin bevat de informatieve kern van de mededeling. Het zou interessant zijn om nader te onderzoeken in welke mate deze strategie ook in andere tekstsoorten en in eerdere taalstadia gebruikt wordt.

Hiermee zijn we beland bij het centrale thema van de bijdrage van Coussé: passieve zinnen met een achtergeplaatst onderwerp. Coussé constateert in het onderzochte corpus een relatief hoog percentage van onderwerpen in extrapositie en een toename van het aantal achteropplaatsingen in de loop der tijd. Die toename blijkt vooral op het conto van subjectszinnen te schrijven te zijn. Een en ander wordt in verband gebracht met de semantische rol van het passieve subject als patiens enerzijds en de grammaticalisatie van passieve zinnen - in traditionele termen uitgedrukt: de overgang van een naamwoordelijk naar een zuiver werkwoordelijk gezegde - anderzijds. Wat het eerste betreft: ik weet niet zo zeker of je nominale constituenten en complete (bij)zinnen zomaar op een hoop kunt gooien door ook de zinnen de rol van patiens toe te kennen. Je kunt wel stellen dat zinnen als aparte propositie een abstracte(re) vorm van onderwerp zijn. Wat het tweede betreft: de grammaticalisatie van de combinatie van worden + deelwoord kan misschien wel (mede) verklaren waarom er steeds meer subjectszinnen voorkomen, maar dat zegt mijns inziens op zich nog niets over het waarom van extrapositie. Het achteropplaatsen van bijzinnen is vermoedelijk veeleer te verklaren uit een algemene tendens om afzonderlijke proposities niet in elkaar te schuiven, maar op elkaar te laten volgen, dus bijvoorbeeld een bijzin aan het begin (op de eerste zinsplaats) of aan het eind (op de laatste zinsplaats) van de hoofdzin te zetten.

Een laatste kanttekening die ik wil maken is de volgende. Net als in Coussé (2009) wordt ook hier naar mijn gevoel ten onrechte gesuggereerd dat wat achter de tweede pool van de zin staat, per definitie focusgeschikt is - dat zou misschien nog te verdedigen zijn - of altijd in focus staat of zelfs nieuwe informatie introduceert. Dat hoeft niet per se het geval te zijn. Iets kan ook achteraan in de zin staan als een soort bijkomstigheid of als een soort afterthought (zie onder meer de ANS 1997: 1356 e.v.; Haeseryn 1998; Shannon 1993). Ik volsta hier met enkele voorbeelden die ik uit plaatsgebrek slechts summier toelicht. 
(1 la) Als ik tijd heb |zal| ik onderweg wel wat boodschappen |doen.|

(11b) Ik |zal| als ik tijd heb onderweg wel wat boodschappen |doen.|

(11c) Ik $\mid$ zal $\mid$ onderweg wel wat boodschappen |doen| als ik tijd heb.

(12a) Ik $\mid$ heb | gauw nog even |afgewassen| toen ze allemaal weg waren.

(12b) Ik $\mid$ heb| pas |afgewassen| toen ze allemaal weg waren.

(13a) Misschien |kunnen| we buiten |eten| als het mooi weer is.

(13b) We |kunnen | alleen maar buiten |eten | als het mooi weer is.

(14) De voorstellen |zijn| niet |aangenomen|, zoals/wat te verwachten was.

(15) De commissie |wilde| niet |accepteren| dat haar voorstel afgewezen was, zoals/wat te verwachten viel.

In (11) ligt de informatieve kern in alle drie de volgordevarianten (dus ook in (11c)) bij 'boodschappen doen'. Wat in het bijzinnetje staat geeft veeleer een omstandigheid aan. Bij (12) en (13) geven de respectieve focuspartikels aan dat er alleen in de b-varianten wat voor te zeggen is dat de bijzin in focus staat en in (14) en (15) is de cursief gedrukte bijzin als een afterthought op te vatten. Voor de achteropplaatsing van bijzinnen kan dus beter een tweedeling gemaakt worden in gevallen met de kenmerken [+ complex; + focus] en gevallen met de kenmerken [+ complex; - focus]. 